\title{
Impact on Human Health of Particulate Matter Arising from Atmospheric Pollution
}

\author{
Clara Rodrigues Pereira'; ${ }^{1}$ Ĺlian Lefol Nani Guarieiro ${ }^{2 *}$ \\ ${ }^{1}$ Centro Universitário Senai Cimatec, Master's degree course on Sustainable Development; ${ }^{2}$ Centro Universitário Senai \\ Cimatec, Integrated Campus of Manufacturing and Technology; Salvador, Bahia, Brazil
}

\begin{abstract}
Studies show that exposure to particulate matter (PM) from vehicular combustion processes can pose severe risks to human health since the impact degree of PM on the respiratory system will depend on its size and composition. Thus, the objective of this study was to perform a systematic review on this topic, searching information that can highlight causes and solutions that may allow a greater understanding of this problem. We concluded that China is a country that stands out in the number of deaths caused by the emission of PM, given a highly polluted urban scenario. Besides, fine particles (PM2.5) are the most recurrent incidence of respiratory disease, as they are emitted mainly by industrial activities and vehicular emissions.
\end{abstract}

Keywords: Particulate Matter. Human Health. Respiratory System. Vehicle Emissions.

The global-technology-development evolution of urban cities contributes to the increase in air pollution. This situation calls attention to many organizations thatlook for actions thatcan reduceair pollution, such as the United Nations. It presented the 17 goals to improve the world in a time delta to meet them by 2030 . This primary mission is to put into practice actions that can lead to the end of poverty, the prosperity and well-being for all, protect the environment, and face climate change [1]. Within this scenario, Goal 7 (Affordable and Clean Energy) stands out, as it shows measures to reduce significant pollution sources in the external environment, such as the participation of renewable energy in the global energy matrix and access to clean energy technologies [1].

In this scenario, substances that are emitted by industries, car exhausts, and other urban activities are deposited on road pavements and in human circulation spaces [2]. These factors contribute to the increase of air pollution and exposure of the individual to this environment [2]. Data from

Received on 25 September 2019; revised 28 October 2019. Address for correspondence: Dr. Lílian Lefol Nani Guarieiro. Centro Universitário SENAI CIMATEC. Av. Orlando Gomes, 1845, Piatã. Zip Code: 41650-010. Salvador, Bahia, Brazil. E-mail: lilian.guarieiro@fieb.org.br. This study was selected from the V International Symposium of Innovation and Technology - SIINTEC (October 2019).

J Bioeng. Biotech. Appl. Health 2019;2(4):136-140.

(C) 2019 by SENAI CIMATEC. All rights reserved. the World Health Globalization (WHO), in 2016, showed that air pollution in cities and rural areas is responsible for 4.2 million premature deaths per year due to exposure to particulate matter (PM), which causes cardiovascular, respiratory and carcinogenic diseases [3]. This information shows the level of impact that the PM can have on human health. But why? What causes these particles to damage our bodies? How are they formed, and what is their origin?

Atmospheric PM consists of mixtures of airborne solid particles that vary in size and chemical composition. They can be comprised of nitrates, sulfates, organic and elemental carbon, organic compounds, biological compounds, and metals (iron, copper, nickel, zinc, and vanadium) [4]. They derive from natural sources, which do not involve human activities (sea salt particles, windblown sand, volcanic ash), and anthropogenic sources, which come from urban processes (industrial processes, vehicles, and fuels) [5].

The length of the aerodynamic diameter of PM is the main factor that determines the capacity of particle transport in the atmosphere and the penetration capacity in the human respiratory system [4]. The PM can be classified into three groups: Coarse particles (PM10), which include diameter sizes between 2.5 and $10 \mu \mathrm{m}$, fine particles (PM2.5) with a diameter less than $2.5 \mu \mathrm{m}$, and ultrafine particles (PM0.1) with diameter less than 0,1 $\mu \mathrm{m}$ [4]. Coarse particles (PM10) are defined 
as primary particles once they are directly emitted into the atmosphere [4]. Fine particles (PM2.5) are classified as secondary since their formation in the atmosphere occurs through chemical reactions [4].

The emission of particulate matter plays a prominent role in the literature by showing severe diseases that may be caused by the impact of PM on the respiratory tract, such as cardiovascular diseases, respiratory diseases, and diseases of the nervous system [2]. Therefore, some monitoring ways are already being adopted to identify the level of PM emitted by urban activities [3]. They can be fixed or mobile stations that have adequate tools to define which sizes are most emitted and their emission source [3]. However, it is vital for the evaluation of human exposure to PM and its impact on them. Thus, mathematical modeling aimed at simulating MP deposition in the lung is one of the critical tools in assessing its impact on health [6].

So, the main goal of this study was to accomplish a systematic review on the impact of particulate matter on human health when emitted by urbanization processes.

\section{Method}

The method applied for the development of this study was the systematic review (Figure 1). This method was developed according to the following steps: i) the keywords used were "particulate matter", "dry deposition", "wet deposition", "vehicular emission", "lung deposition"; ii) the databases used for research were Scopus (www. scopus.com), Science Direct (www.sciencedirect. com) and Capes (www.periodicos.capes.gov.br); iii) the established search period was from 2009 to 2019 ; iv) we verified if the title of the articles had the determined keyword; v) the abstracts were read according to the established filter (Figure 1).

\section{Results and Discussion}

One of the steps used in the systematic review was the time interval (2009 to 2019) stipulated in the search for materials related to the theme presented. Therefore, Graphic 1 represents how the study concerned has evolved over the years, proving that the theme has drawn attention, presenting a high degree of importance (Total of 120 articles).

From the systematic review performed in this study, it was possible to direct the research to the impact that the MP, arising from urbanization processes, can have on human health. One hundred twenty articles relevant to the theme were obtained. Through the selection of studies, the countries that researched this problem the most were identified (Graphic 2).

China presented $40 \%$ of the articles selected for the study, which highlight the impact of PM on the health of individuals (Graphic 2). The main reason for this happens because of the air pollution in China, which has become the fourth significant health risk in all the world, presenting PM as the central air pollutant [7].

The high degree of pollution in China is recurrent from rapid urbanization and economic development, where most PMs are emitted by anthropogenic activities (industrial activities, vehicle emissions) [7]. Thus, exposure to this particulate represents a vulnerability in human health when deposited in the respiratory tract once the high levels of aromatic polycyclic metals and hydrocarbons are part of PM [7].

Figure 2 ratifies this statement by presenting an illustrative map, which shows data from the year of 2016 on what in each country, the highest lung mortality rates from inhalation of PM are evidenced. On the map, China has a mortality rate between 1500 and 1999 million, with the exact value of 1,830 million deaths caused by PM emission [8].

Exposure to PM is influenced by local conditions such as weather, seasons, topography, particle sources, and others. However, inhalation is the most important way for the human body to contact PM. Its degree of impact is related to the particle size deposited in the respiratory tract [9]. The deposition of PM in the lung occurs in a way 
Figure 1. Flowchart of the systematic review method.
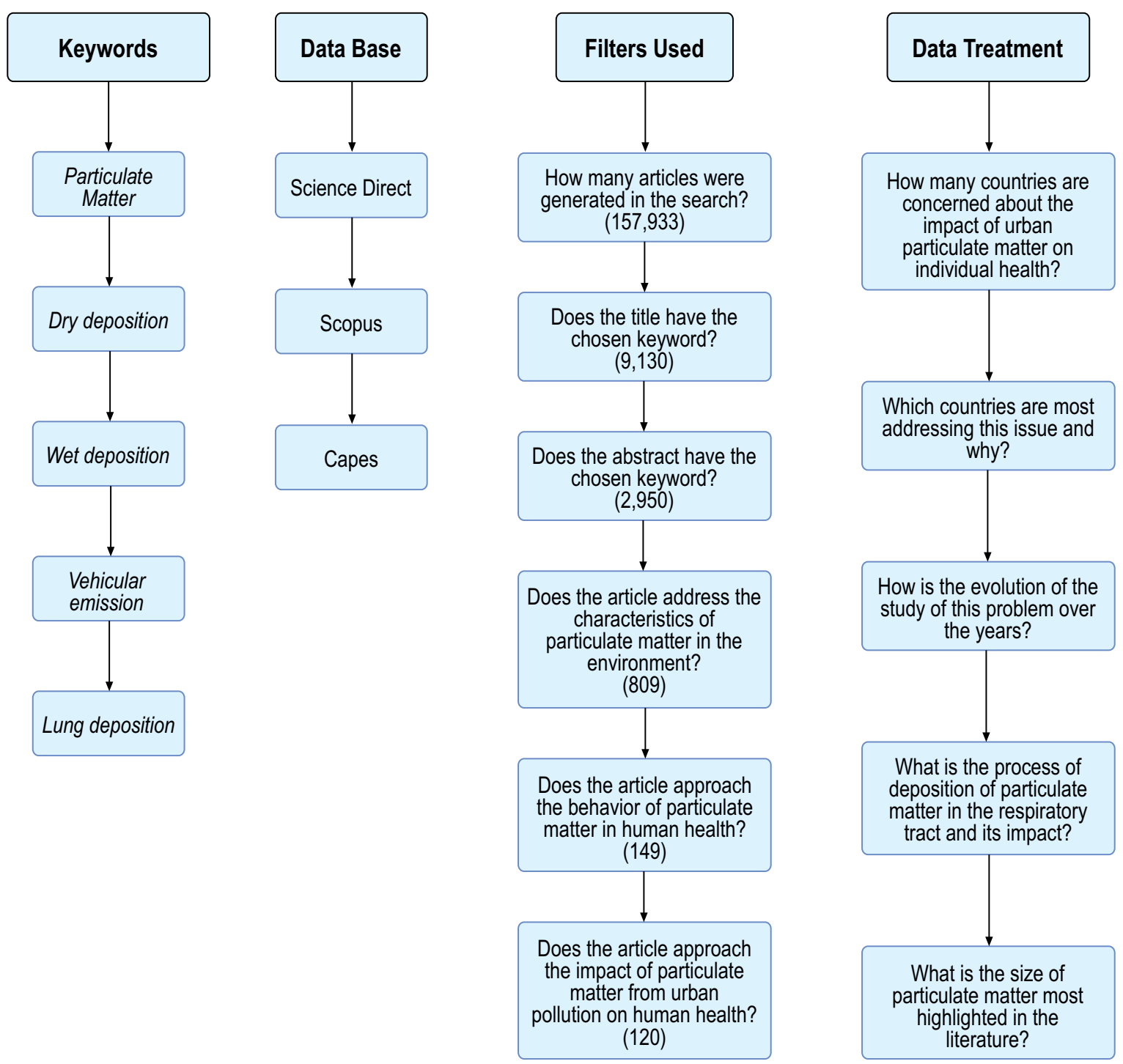

that the smaller the particle, the higher the ability to absorb organic and inorganic compounds, and the higher the ability to penetrate the respiratory tract [4]. The coarse particles (PM10), when inhaled, are lodged in the trachea (upper throat) due to the rubbing of the PM10 with the nasal hair, and then it will be harder to penetrate the expiratory system [4].

The fine particles (PM2.5) were highlighted in the literature as providers of high-risk diseases, and its capacity for higher emission is from vehicles exhaust (product of incomplete combustion of internal combustion engines) [10]. When inhaled
(PM2.5) travels through the bronchioles and alveoli (where gas exchange occurs) and can penetrate the bloodstream causing significant health problems [4]. The impact of PM10 and PM2.5 is found in the literature as they are related to other particle sizes, such as PM1.0, which, like PM2.5, has a more exceptional ability to penetrate deeper into the human being [11]. It can aggravate asthma, bronchitis, and other respiratory problems, leading to cardiovascular symptoms [11].

Exposure to PM can promote the incidence of high-risk diseases such as respiratory problems, exacerbation of the chronic respiratory disease, 
Graphic 1. Percentage list of articles that approach the theme published over the years.

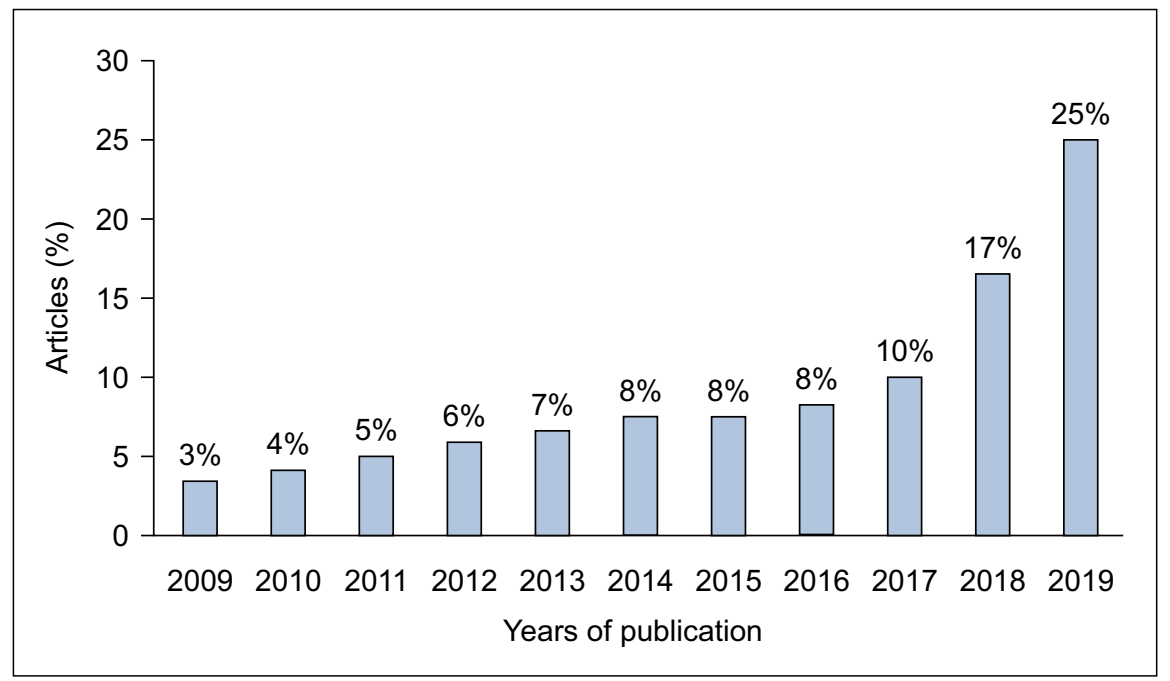

Graphic 2. List of countries that published the research theme the most.

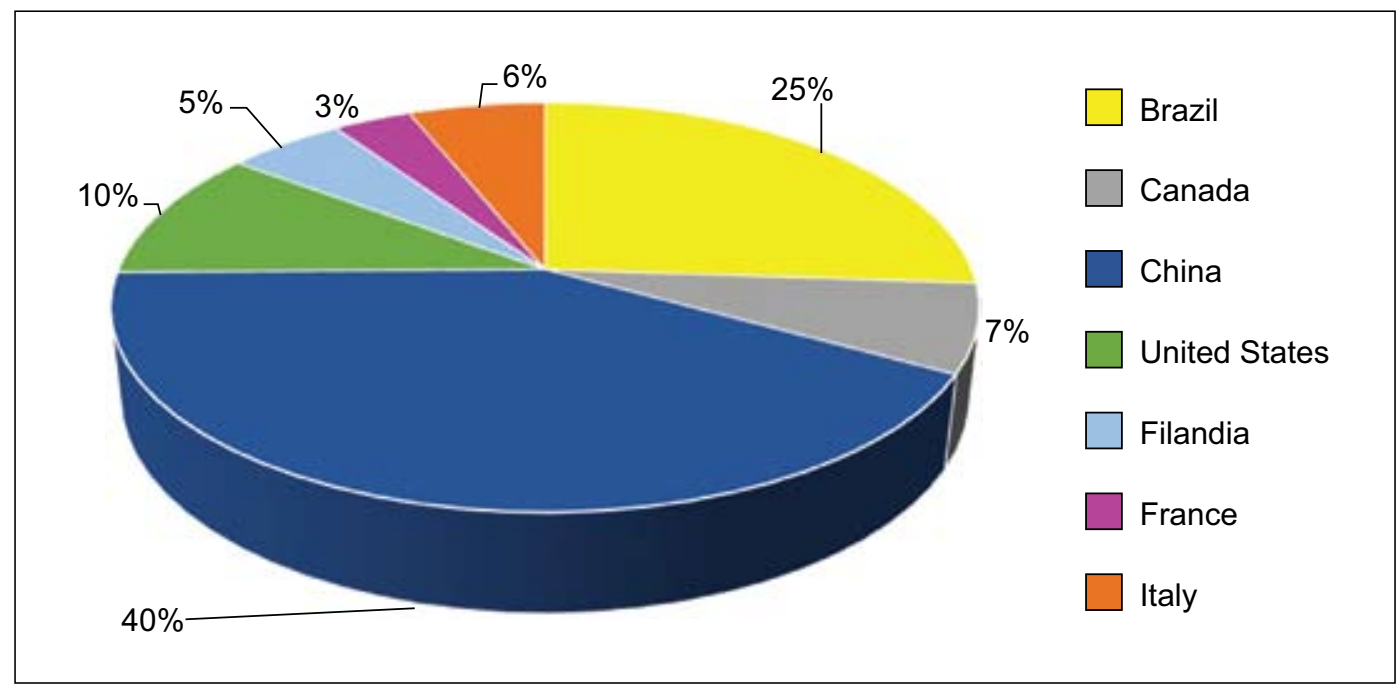

decreased lung function, premature mortality, as well as carcinogenic and mutagenic risks [4]. The PM emitted by the combustion of fuels is comprised of carbon, sulfur dioxide, unburned hydrocarbons, and some metals [12]. They have a strong relationship with the risk of lung cancer, as they cause damage to human DNA, by promoting breaks and alterations in the genetic chain (mutagenic effects) [12].

Therefore, because of their genotoxic (mutagenic) compounds, the emitted particles, especially smaller ones, have a high capacity to induce carcinogenic effects [4]. They can develop symptoms of lung cancer, in addition to other effects such as breathlessness, chest discomfort and pain, loud cough, and wheezing [4]. Children are more likely to be affected by the impact of $\mathrm{PM}$ in the respiratory tract as it can compromise lung development and function. Exposure to an excessive level of fine particles can mainly increase respiratory problems and carcinogenic effects [4]. 
Figure 2. Mortality and disease rates caused by ambient air pollution.

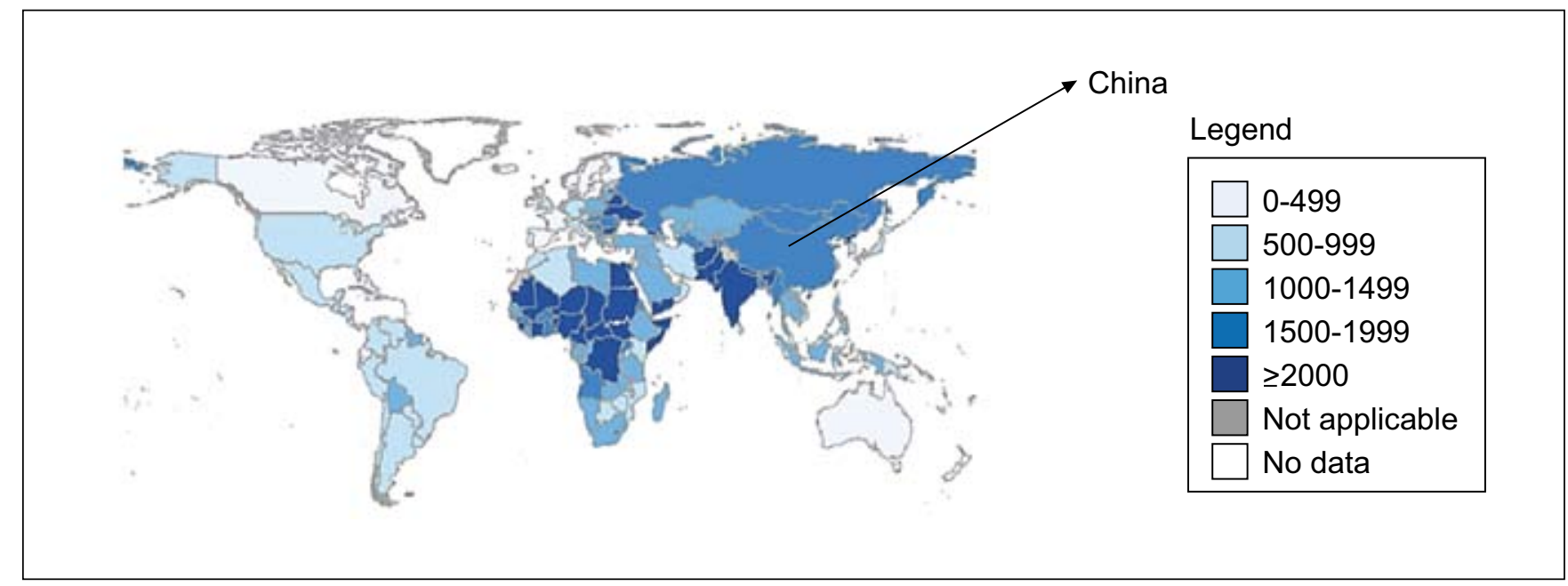

Source: WHO, 2018 [8].

\section{Conclusions}

This article focused on the impact that PM can have on human health, using a systematic review as a resource to obtain information in the literature to prove the problem mentioned. China has been identified as the country that publishes most articles on the subject, and this is justified by the fact that it has the highest degree of pollution from anthropogenic activities. The intense occurrence of this type of activity provides a high emission of fine PM, which, when deposited in the respiratory tract, can cause irreversible damage to human health.

\section{References}

1. ONU. 17 Objetivos para transformar nosso mundo. Available on: $<$ https://nacoesunidas.org/pos2015/ods7/>. Access: Aug. 02, 2019.

2. Ali MU et al. A systematic review on global pollution status of particulate matter-associated potential toxic elements and health perspectives in urban environment. Environmental geochemistry and health. 2018:1-32.

3. WHO. Ambient (outdoor) air quality and health. Available on: <https://www.who.int/en/news-room/ fact-sheets/detail/ambient-(outdoor)-air-quality-andhealth/>. Access: Aug. 05, 2019.
4. Kim K-H, Kabir E, Kabir S. A review on the human health impact of airborne particulate matter. Environment International. 2015;74:136-143.

5. $\mathrm{Hu} \mathrm{Z}$ et al. Concentrations and source apportionment of particulate matter in different functional areas of Shanghai, China. Atmospheric Pollution Research. 2014;5(1):138-144.

6. Dedelé A, Miskinyté A. Seasonal and site-specific variation in particulate matter pollution in Lithuania. Atmospheric Pollution Research. 2019;10(3):768-775.

7. Wang, S. et al. Size-fractionated particulate elements in an inland city of China: Deposition flux in human respiratory, health risks, source apportionment, and dry deposition. Environmental Pollution. 2019;247:515-523.

8. WHO. Mortality and burden of disease from ambient air pollution. Available on: <https://www.who.int/en/newsroom/fact-sheets/detail/ambient-(outdoor)-air-qualityand-health/>. Access: Aug. 05, 2019.

9. Guarieiro LLN, Guarieiro ALN. Vehicle emissions: What will change with use of biofuel? In: Biofuels -Economy, Environment and Sustainability. [s.1.] InTech, 2013.

10. Wong YK et al. Estimating contributions of vehicular emissions to PM2. 5 in a roadside environment: Amultiple approach study. Science of The Total Environment. 2019;672:776-788.

11. Karri RR et al. Modeling airborne indoor and outdoor particulate matter using genetic programming. Sustainable Cities and Society. 2018;43:395-405.

12. Guerrera E et al. Cytotoxicity and genotoxicity of sizefractionated particulate matter collected in underground workplaces. Air Quality, Atmosphere \& Health. 2019;12(3):359-367, 2019. 